\title{
واقع تكوين مربيات الطفولة الأولى في الجزائر
}

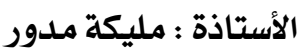

كلية العلوم الإنسانية والاجتماعية

جامعة محمد خيضر بسكرة، بسكرة، الجزائر

الملخص:

إن الإعداد الجيد لمربية الطفولة مسألة ضرورية وحتمية لأنه حجر

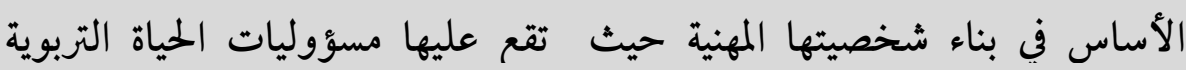

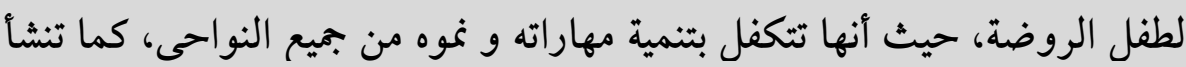

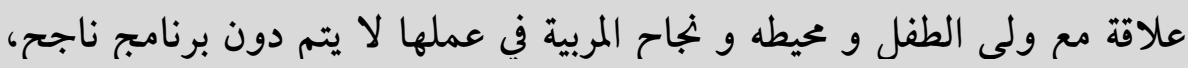
لذلك يجب أن تولى أهمية كبرى لبرامج إعداد ميطه و مربيات الطفولة.

من هنا جاءت فكرة هذه الدراسة للكشف عن جوانب تكوين من

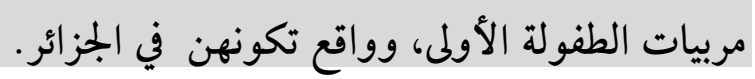

\section{Résumé}

L'éducateur de la première l'enfance intervient auprès d'enfants de 3 à 5 ans en service de garde. Dès la mise en contact avec son milieu de travail, il est appelé à répondre aux besoins de base de l'enfant. Pour ce faire, il doit assumer la sécurité de l'enfant, évaluer les besoins de ce dernier (et évaluer la pertinence des interventions faites., également appelé à jouer un rôle de partenariat auprès des parents et les autres partenaires du milieu de l'enfant.

Cet article évidence les défirent aspec de la formation de L'éducatrice de la premiére enfance. 
يعتبر الإعداد الجيد لمربية الطفولة مسألة ضرورية وحتمية لأنه حجرا

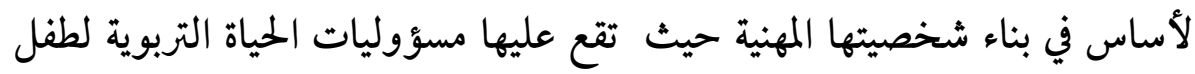

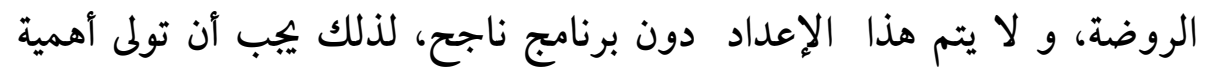
كبرى لبرامج إعداد مربيات أطفال الروضة.

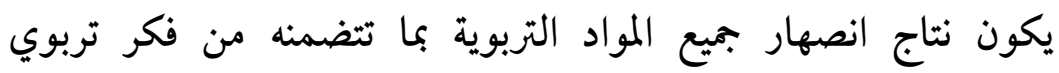

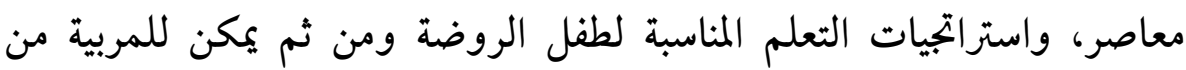

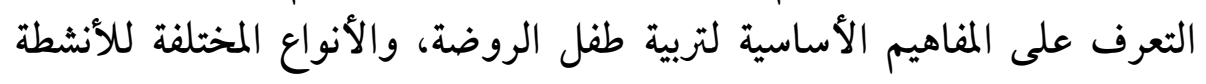

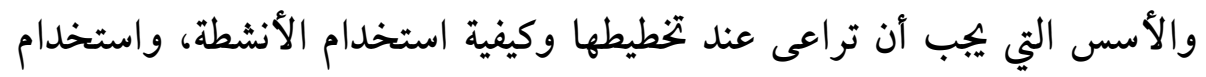

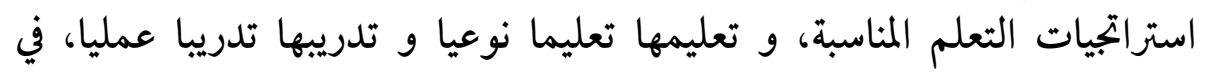

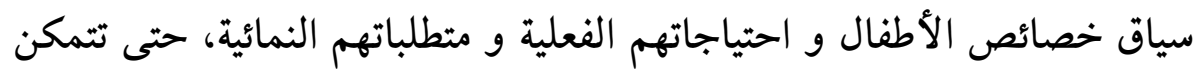

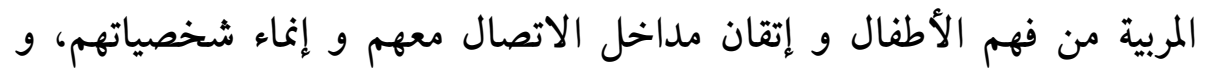

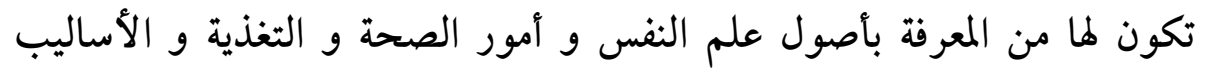

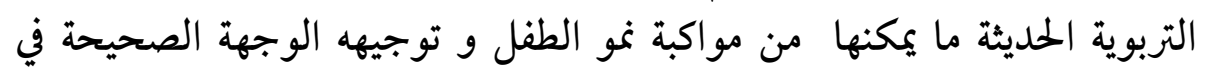

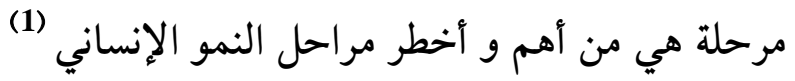

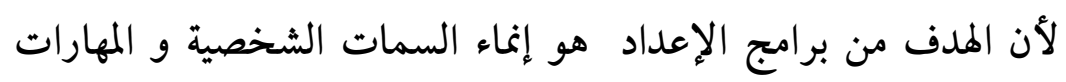

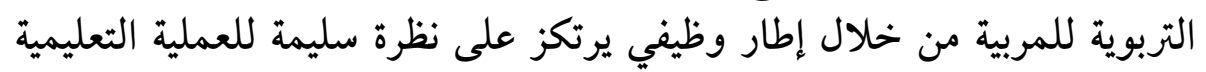

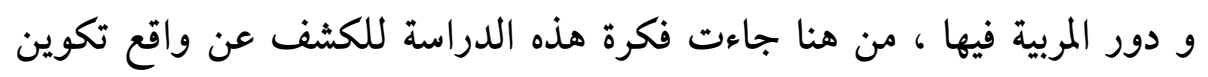

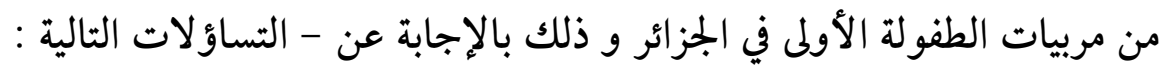
1 - ما هي الجوانب التي يتم فيها تكوين مربية الطفولة الأولى؟ هربيا؟ 2- ما واقع تكوين المربية في الجزائر منذ ظهوره إلى يومنا هذا؟ 3- ما تقييم تكوين مربيات الطفولة المبكرة في الجزائر ؟

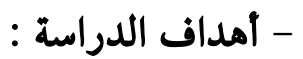


1 - معرفة يختلف الجوانب التي تتكون فيها مربية الطفولة الأولى.

2- معرفة واقع تكوين المربية في الجزائر منذ ظهوره إلى يومنا هذا.

$$
3 \text { - تقييم واقع تكوين المربيات في الجزائر ؟ }
$$

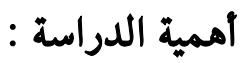

1- إبراز لواقع تكوين مربية الطفولة الأولى في الجزائر .

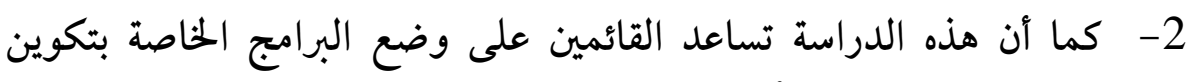

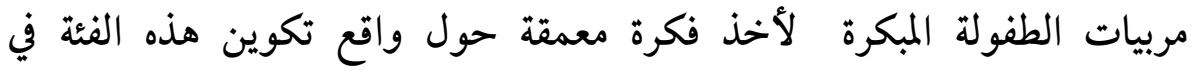

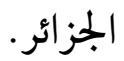

\section{المصطلحات الإجرائة للدراسة :}

1- تكوين مربية: هو تزويد المربية بالمعارف و المهارات و السلوكات لغرض

تأهيلها في ممارسة وظيفتها.

2- المربية : وهي ذلك الشخدص وطئه الأساسي داخل الروضة ر التي تهتم بالطفل

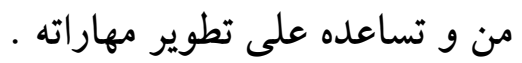

3- الطفولة المبكرة: و نقصد بها المرحلة النمائية من (3-5) سنوات.

ثانيا - جوانب تكوين مربية الطفولة الأولى :

قبل الحديث عن جوانب تكوين المربية من المهم الإشارة إلى المهام الرئيسة

التي تقوم بها المربية أثناء عملها و المتمثلة في (2) :

ل اتخاذ قرارات فيما يختص بالتخطيط والتحضير لغرض التعلم.

ل إعداد و تصميم برنامج الذي يهدف إلى تحقيق أهداف .

$\checkmark$ منظمة لعملية التعلم، من خلال ملاحظتها، وتقويمها لحاجات الأطفال. 
ل مشخصة لقدرات الأطفال من خلال مراقبتها العلمية وتقويمها للنمو

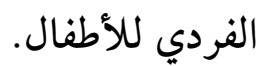

ل إدارتها لعملية التعلم بحيث توفر بيئة تسهم في توفير خبرات تعليمية لجميع الأطفال.

ل مرشدة، وموجهة من خلال مساعدتها لأطفالها بصورة فردية وجماعية ,

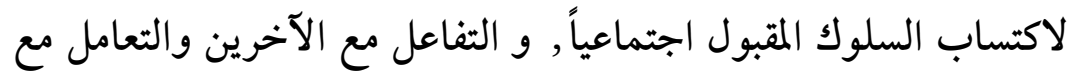
مشاعرهم الذاتية. و يمكن أن نحصر الجوانب الأساسية التي يجب أن ترتكز عليها برامج إعداد المربية بما يلي :

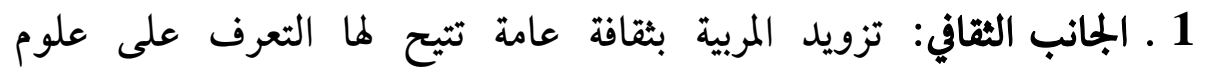

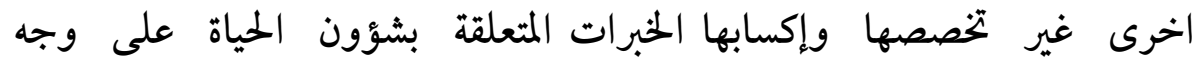

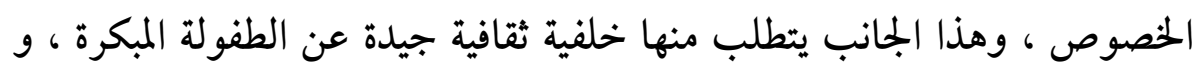

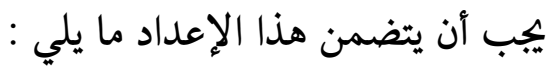

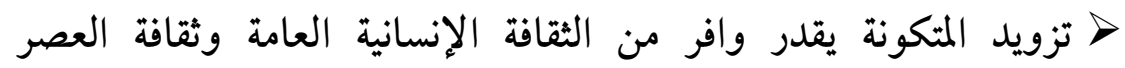

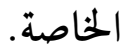

> تمكين المربية من المزج بين الثقافة الإنسانية العامة وثقافة العصر. > تزويد المربية بلغة أجنبية كوسيلة من وسائل الاتصال بالجديد من المنائ الاتجاهات الإنسانية و التقدم العلمي · تونية > تزويد ها بقدر من الثقافة المعلوماتية لمواكبة التقدم التكنولوجي في ميدان

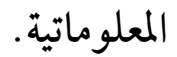


> أما بالنسبة للمواد المقترحة في هذا الجانب فتتمثل في : تاريخ تربية الطفل

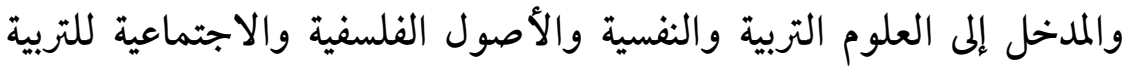

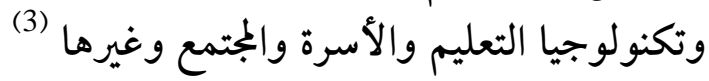

2.

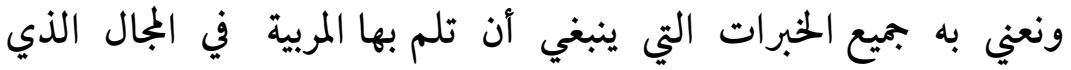

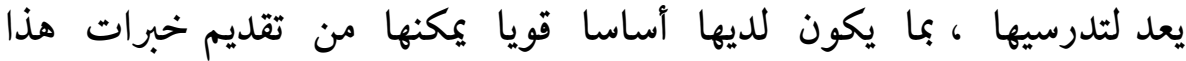

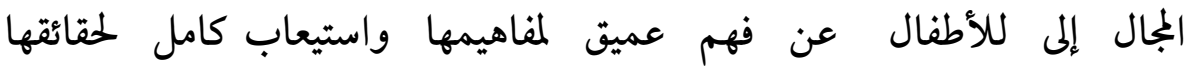

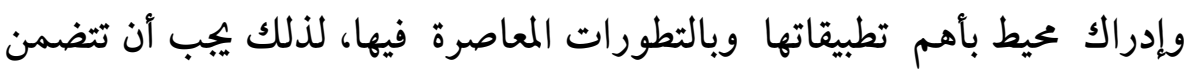

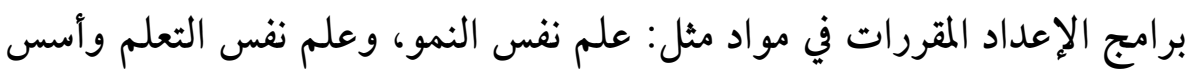

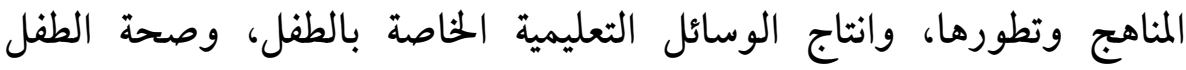

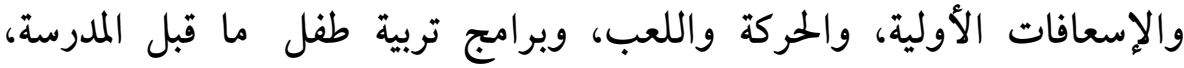

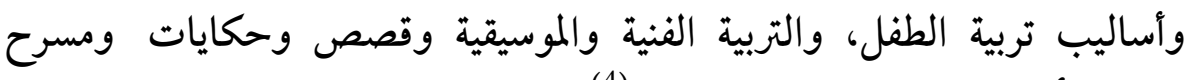
وأدب الأطفال وتنشئة الطفل وحاجاته (4).

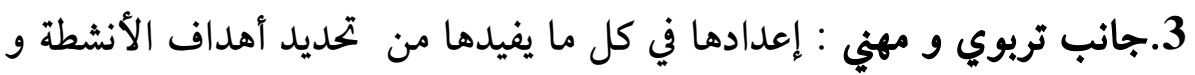

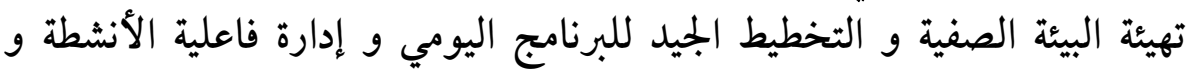

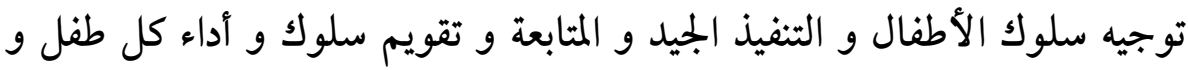

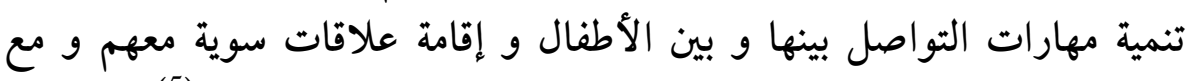

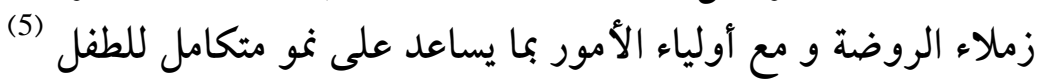

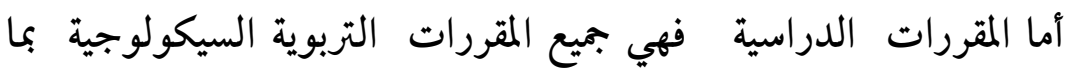

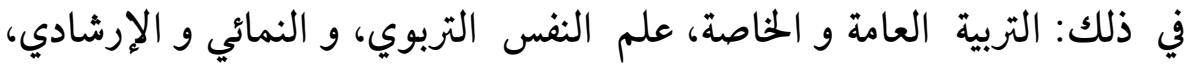

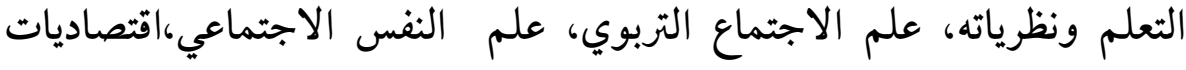

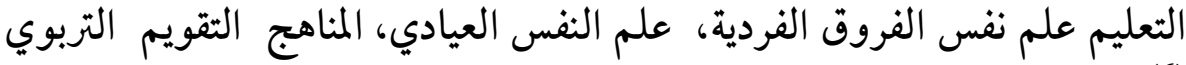

- تكوين مربيات الطفولة الأولى بالجزائر : 
هي أول من نادت بضرورة التربية التحضيرية بحلول العام 1976

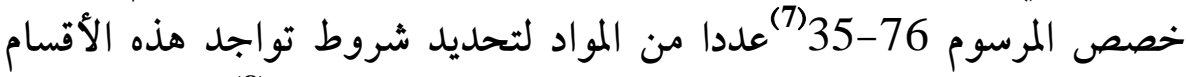

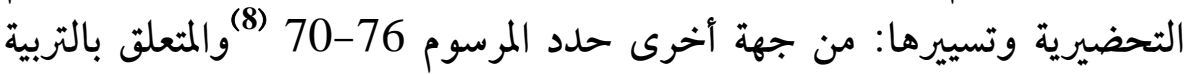

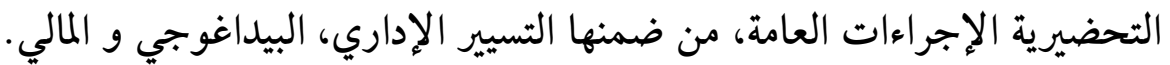

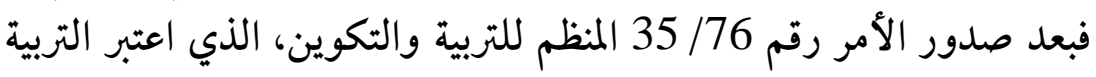

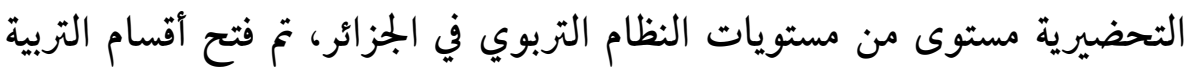

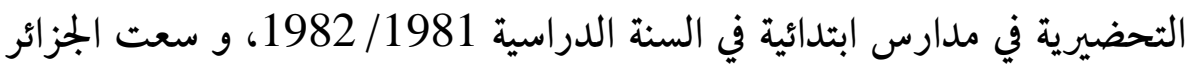

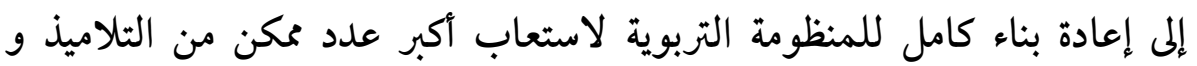

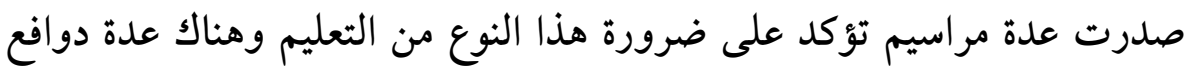

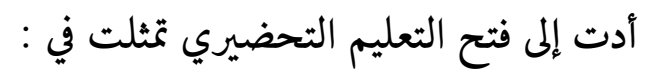

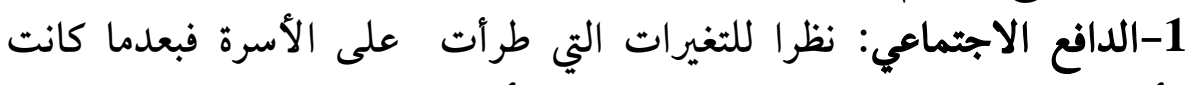

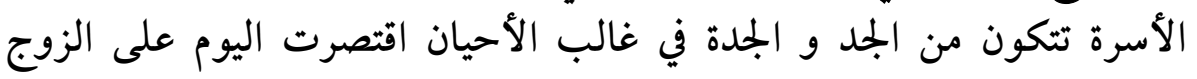

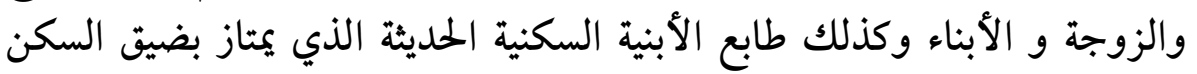
إضافة إلى خروج المرأة للعمل.

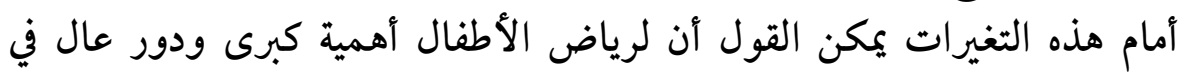

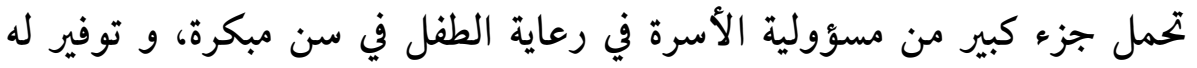

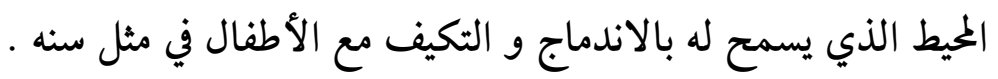

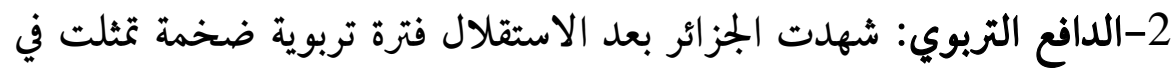

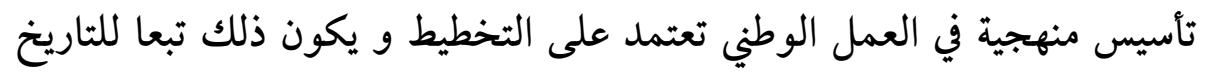

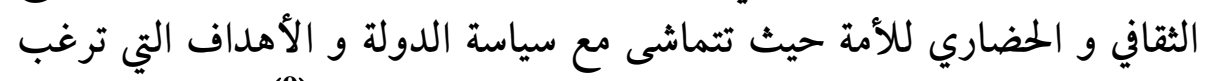

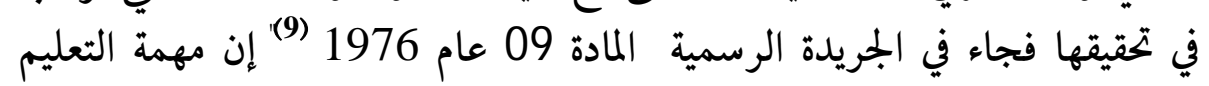

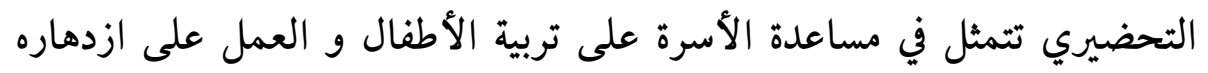

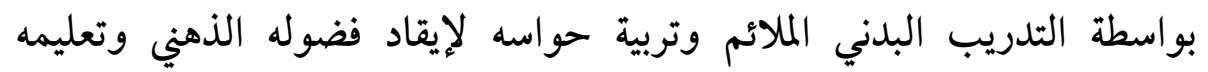


العادات الحسنة وتحضيره للحياة الاجتماعية و إعداد ه للالتحاق بالمدرسة

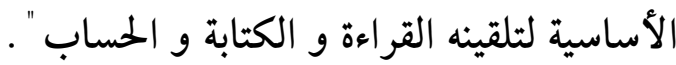

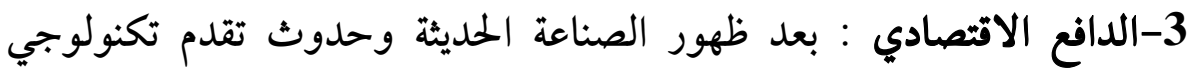

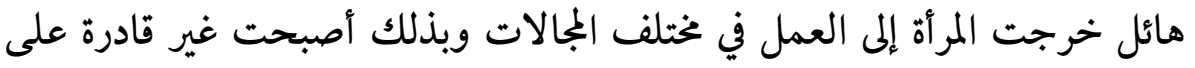

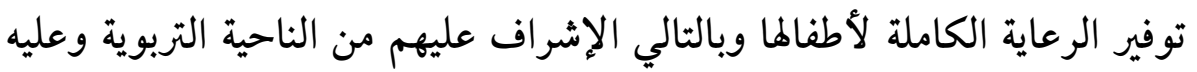

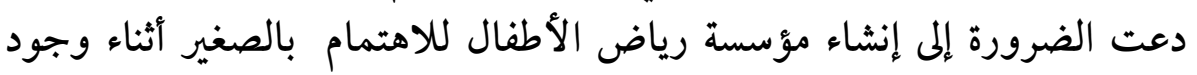

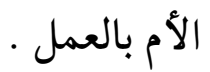

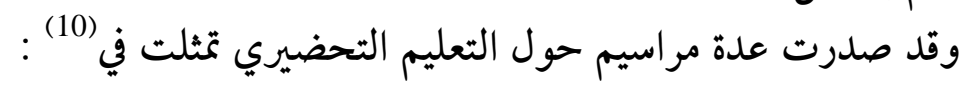

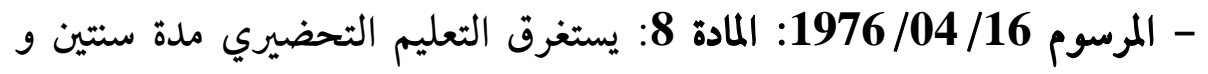

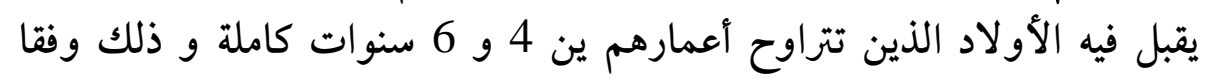

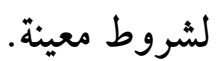

- المادة 11 : تنص على أن لغة التعليم التحضيري هي اللغة العربية: (11)

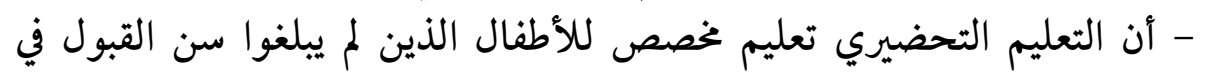

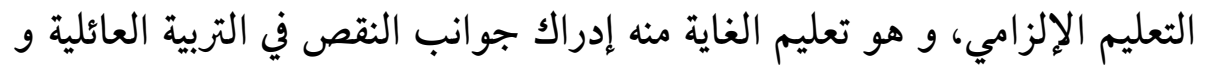

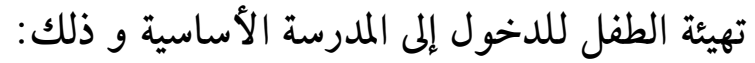
- تعويدهم العادات العملية الحسنة.

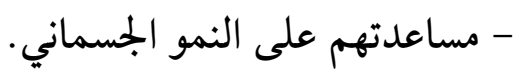

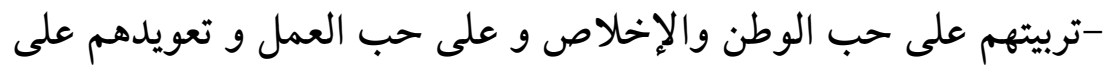

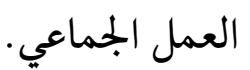
- توفير وسائل التربية الفنية الملائمة.

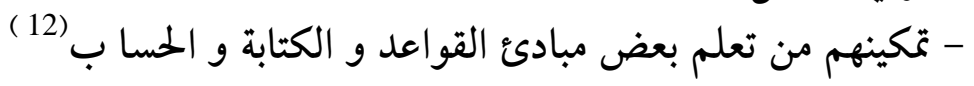

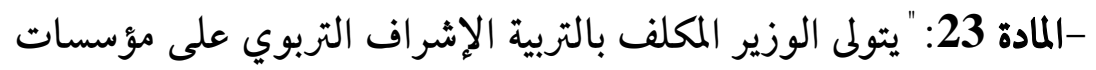

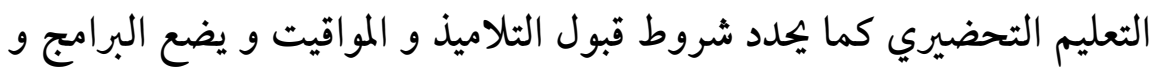

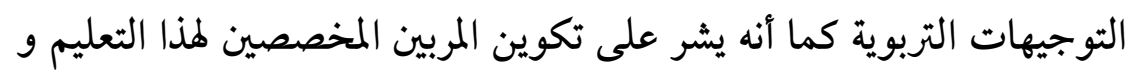

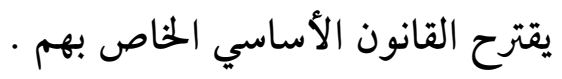


- صدور وثيقة توجيهية تربوية سنة 1984 (13 تؤكد على أهمية التربية التحضيرية

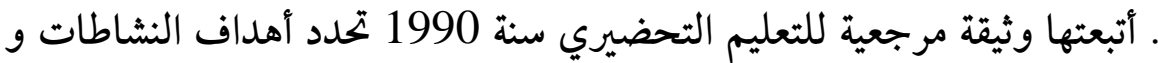
ملمح الطفل و البرنامج المقترح و كيفية تنظيم الفضاء المادي للقسم التحضيري. - في سنة 1996 شهدت التربية التحضيرية في الجزائر تطورا ملموسا بفضل ديعل إنجاز

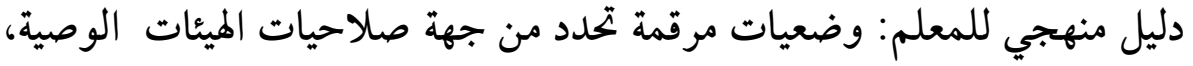

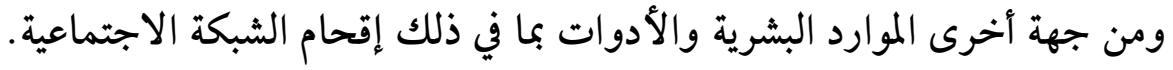
- - في 30 أفريل 2002 صدر قرارا بالشروع في التوسيع التدريجي للتربية

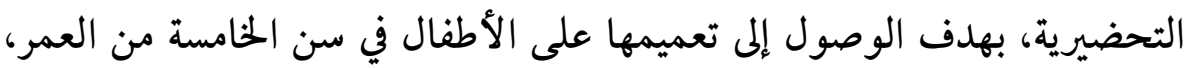

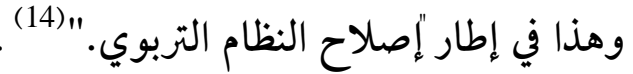

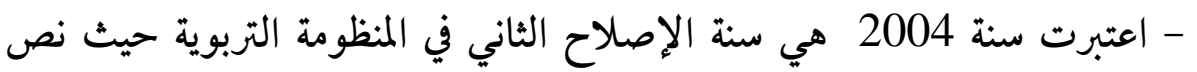

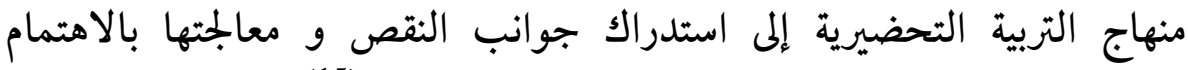

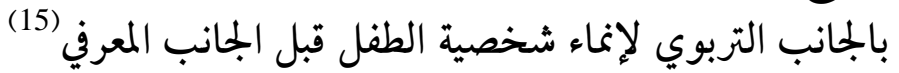

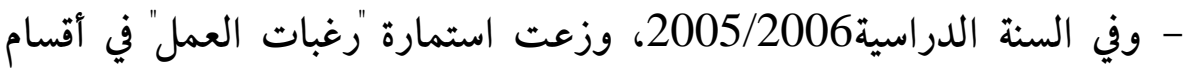
التربية التحضيرية، وقد عبّر 1800 معلما ومعلمة عن رغبتهم في العمل في أقسام التربية التحضيرية في السنة الدراسية 2008/ 2009، وقد نظمت وقدية محليا لهؤلاء المعلمين وغيرهم عمليات تكوينية تخص تقنيات التنشيط في أقسام التربية التحضيرية والعلاقات مع الأطفال. معلم التربية التحضيرية : مئرية

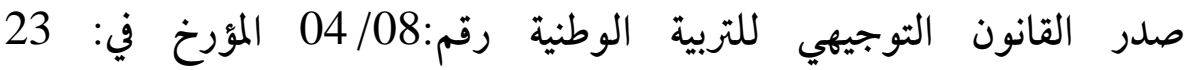

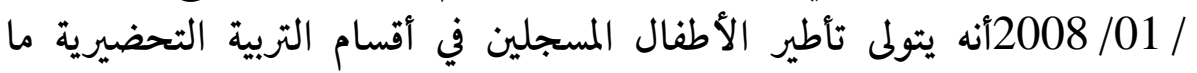
يقرب من 1800 معلم ومعلمة، استفادوا من عمليات تكوينية ميدانية، قبل تحويل

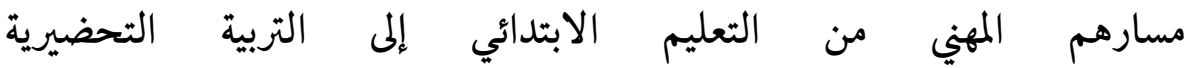

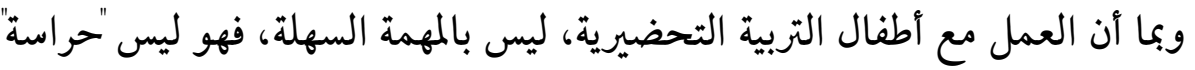
للأطفال وليس تعليما "شكليا" إنها مهمة تجمع بين تهيئة البيئة المدرسية لنمو لثمئه الشخصية وتفتحها تفتحا سويا وسليما، وبين مساعدتهم على بناء تعلّيمات 
"مهيئة للتكيف مع المدرسة بيسر وسهولة. (16). ولذا أكدت تعليمة المنشور الوزاري رقم:32 الخاص بالتدابئ بئر التنظيمية

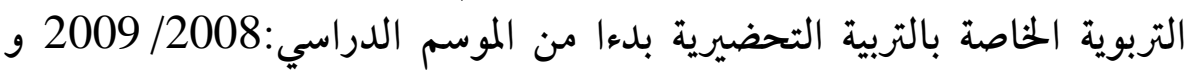

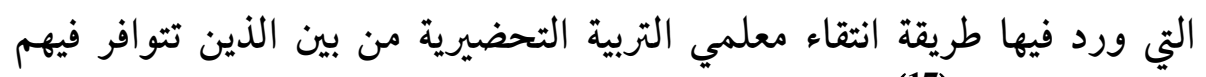
المواصفات التالية (17): ل الميل والاستعداد للعمل مع الأطفال في هذه المرحلة الحرجة.

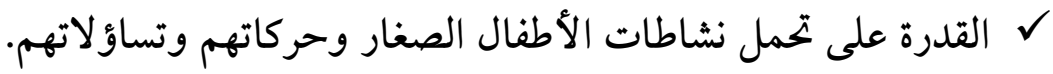
القدرة على التحكم في تقنيات التنشيط مع أطفال هذه المرحلة. ل المشاركة في العمليات التكوينية الخاصة بأقسام التربية التحضيرية. كما نصت التعليمة نفسها على المحاور التي تتناولها عمليات التكوين أثناء

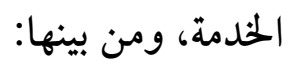
دراسة وتحليل مضموني المنهاج والديل ينها: المرفق له.

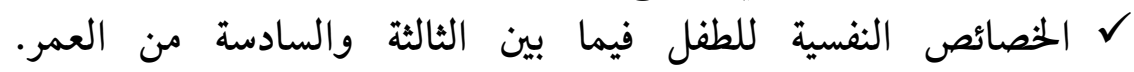
استراتيجيات التعلم لدى الطفل في مرحلة التربية التحضيرية.

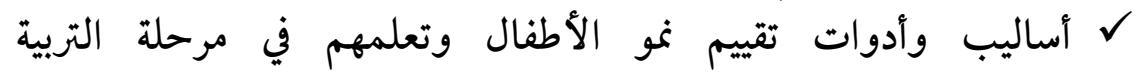
التحضيرية. أشكال تنظيم فضاء قسم التربية التحضيرية، وتسيير الزمن البيداغوجي.

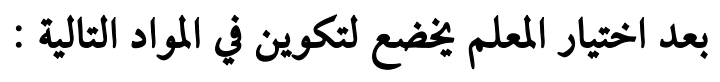
علم نفس النمو. أساليب وأدوات تقييم نمو الأطفال وتعلمهم في مرحلة التربية التحضيرية. دراسة وتحليل مضموني المنهاج والدليل المرفق له. استراتيجيات التعلم لدى الطفل في مرحلة التربية التحضيرية.

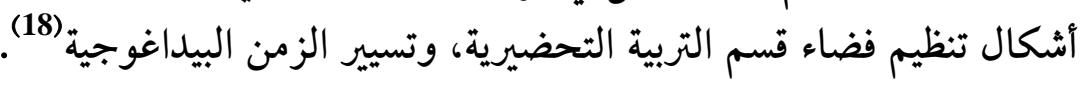

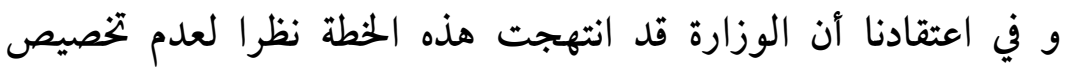
مؤسسات تتكفل بإعداد المعلمين المؤهلين، خاصة و أن الجامعات الجزات الجزائرية لم تفتح 
لحد الآن تخصص في رياض الأطفال خاصة و أن سياسة الإدماج التي اتبعتها

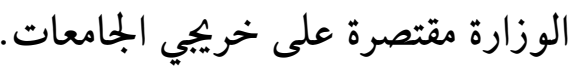

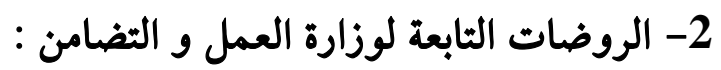

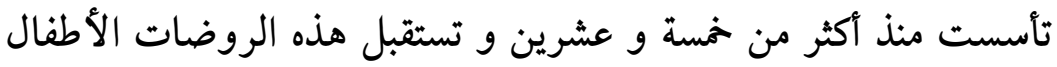

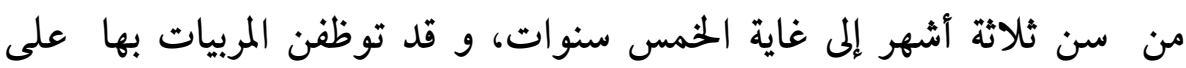

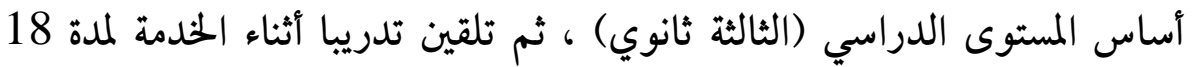

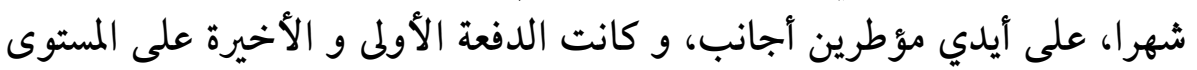

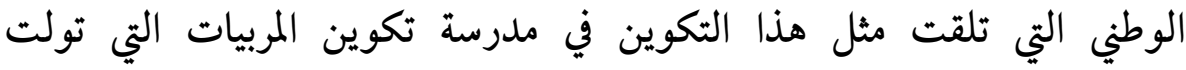

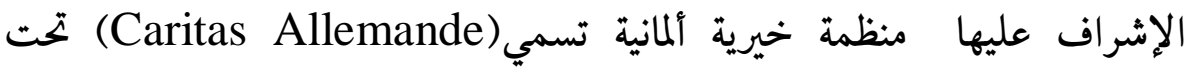

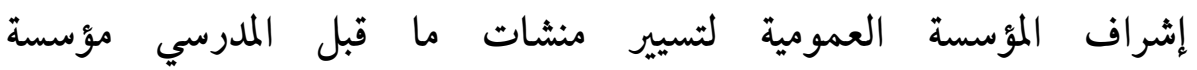

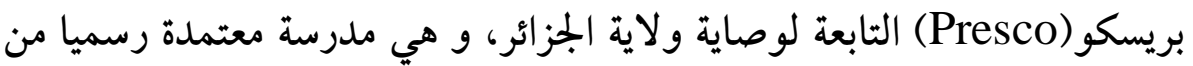

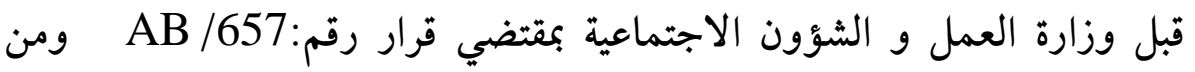

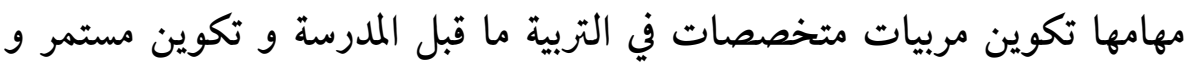

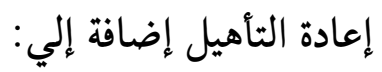
- ضمان تنظيم تربصات لتحسين المهارة ,

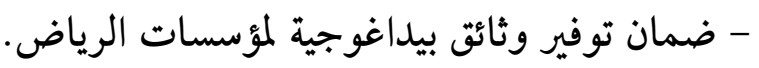

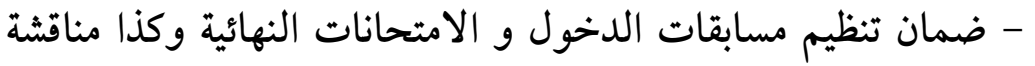
مذكرات التخرج و الإشراف و تنظيم مسابقات الترقية المهنية.

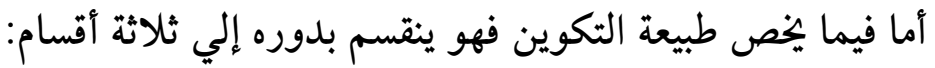

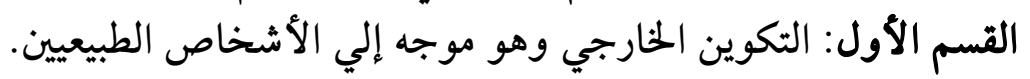

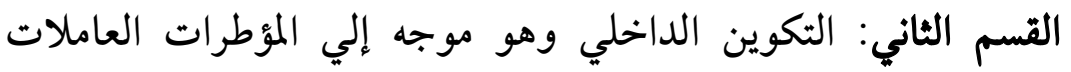
ضمن هذه المؤسسات التربوية.

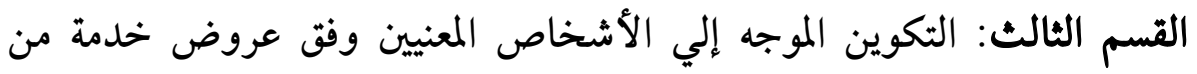

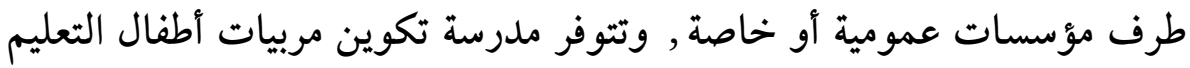

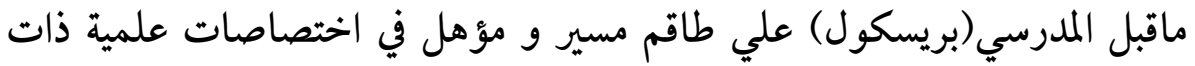


علاقة مباشرة بمحتوي برامج التكوين، وهو حامل لشاهدات جامعية في علوم

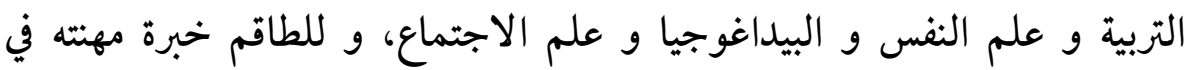

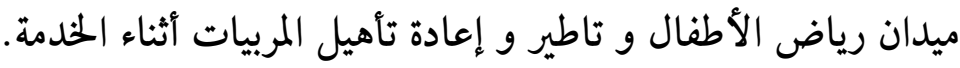

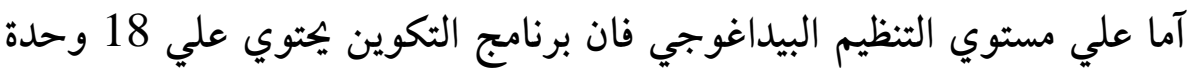

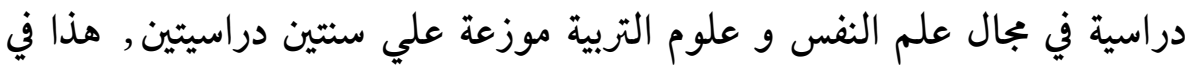

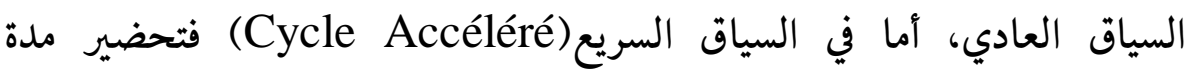
التكوين إلي سداسيين(12شهرا) .

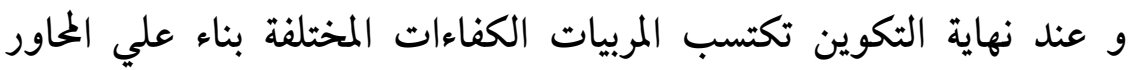

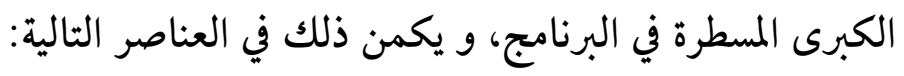
- التخصص بعمق في ثقافة الطفل. - التحكم في التقنيات المنهجية المعاصرة للتربية و التعليم في الرياض. - القدرة علي استيعاب و فهم و استخدام الاختبارات و المقاييس النفسية.

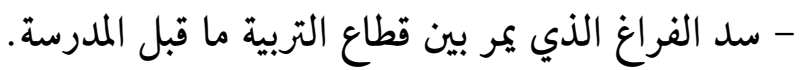

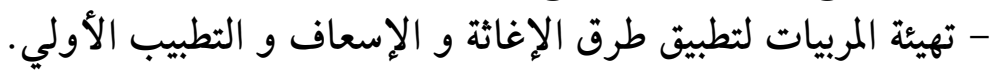

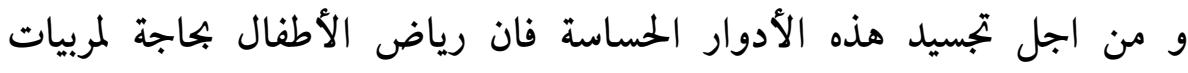

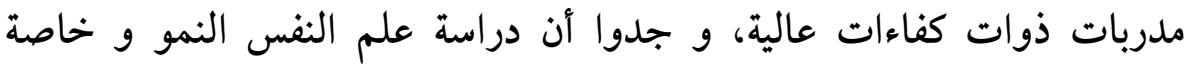

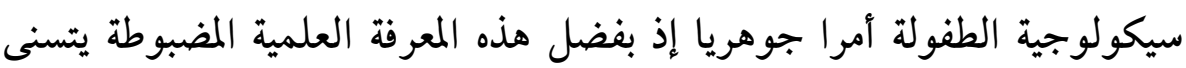

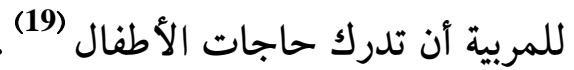
3- الروضات التابعة لوزارة الطاقة و المناجم :

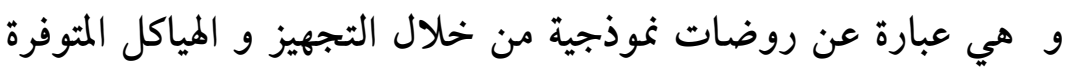
بها، و تستقبل أطفال من سن 3 سنوات إلى غاية 5 سنوات، إلا أن المنات المربيات

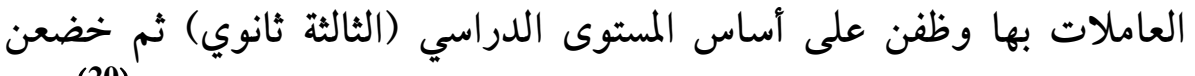

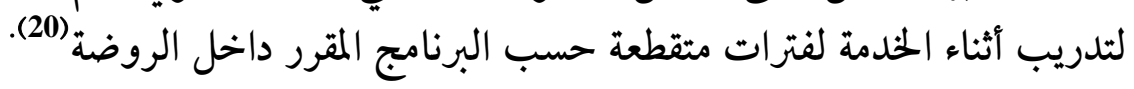
4 - الروضات التابعة لوزارة الدفاع : 


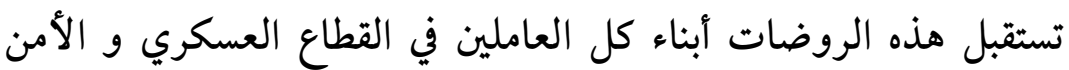

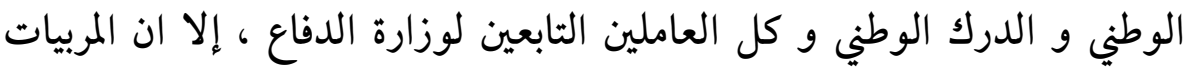

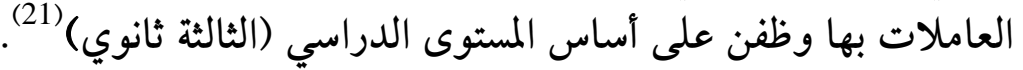

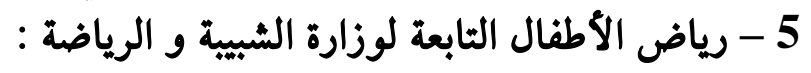

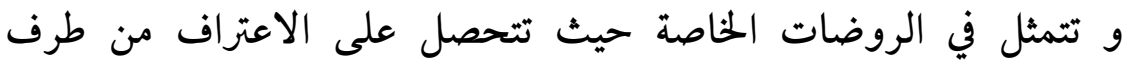

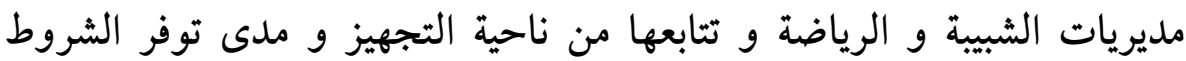

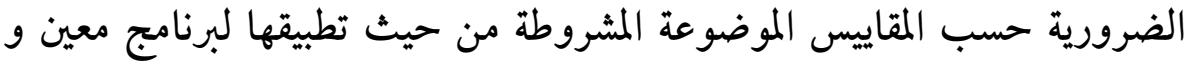

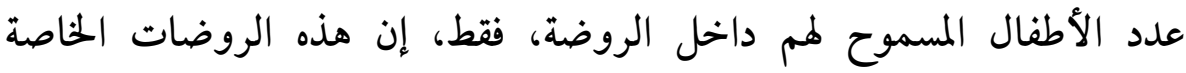

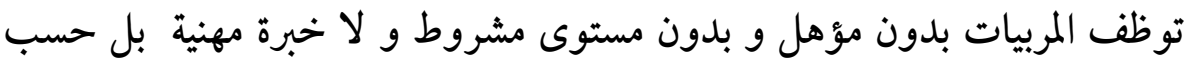

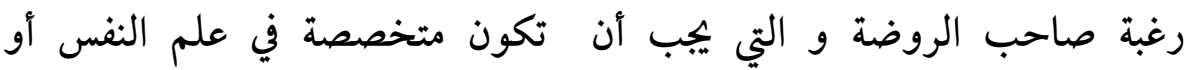

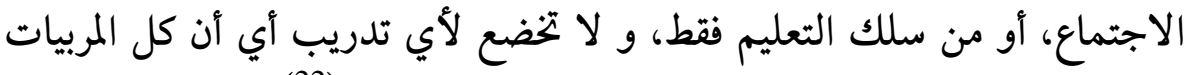

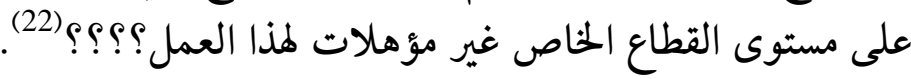

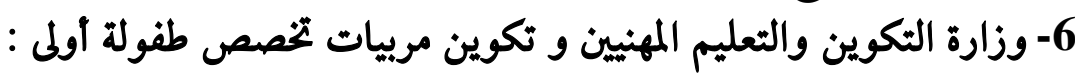

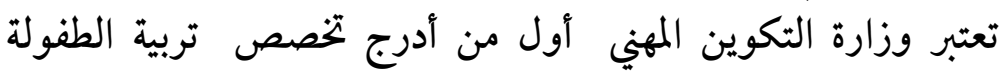

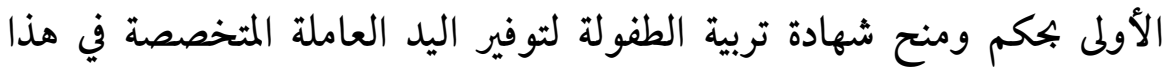

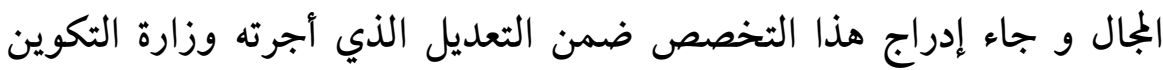

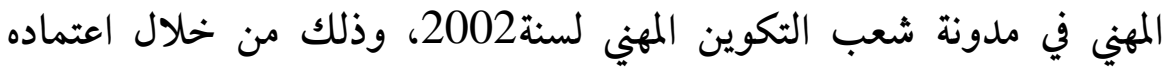

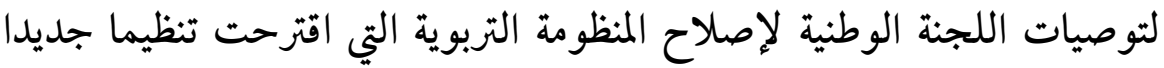

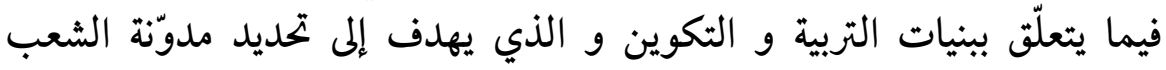

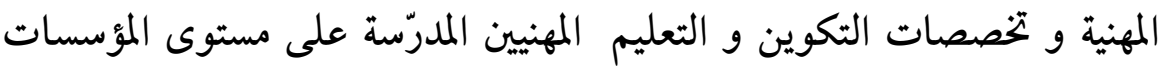

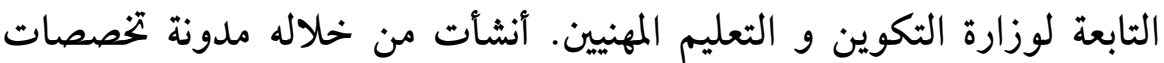

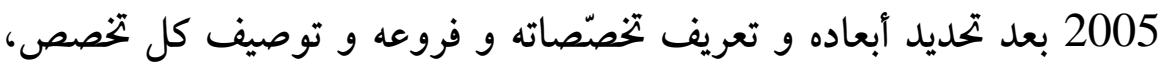

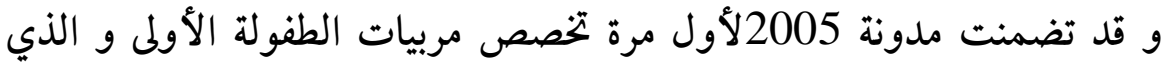

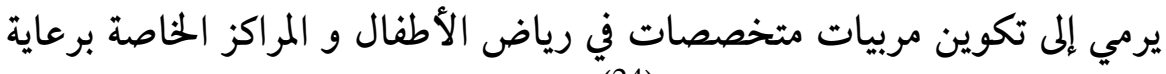
الأطفال متوجة بشهادة تقني سامي (24). 
6-2- المواد الدراسية :تتبع مؤسسات التكوين المهني نظام السداسيات و تتكون المربية خلال 5 سداسيات ،تتلقى فيها المتكونة مواد نظرية المادية المادية

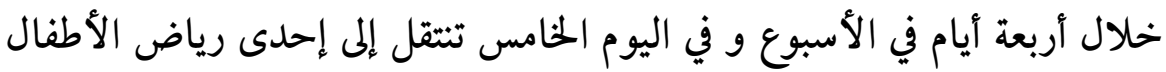

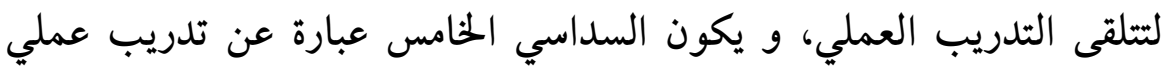

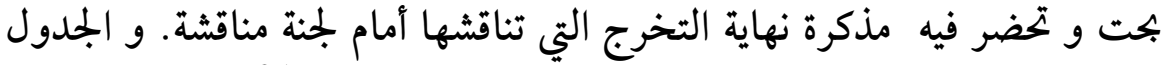

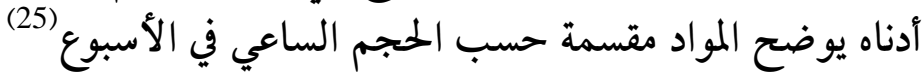
رابعا- تقييم واقع تكوين المربية في الجزائر :

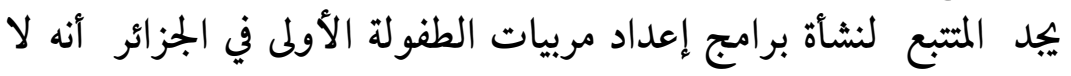

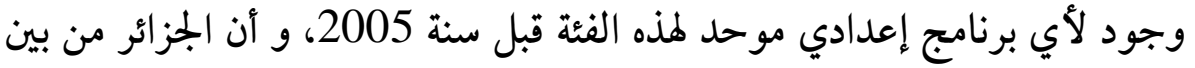

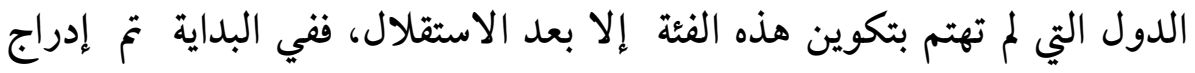

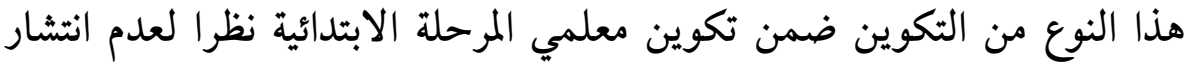

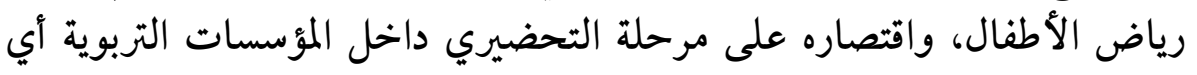

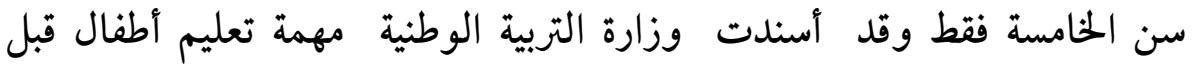

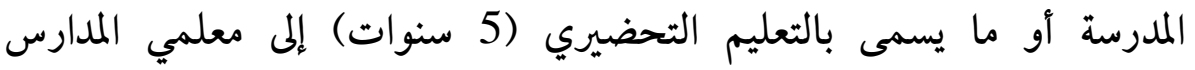

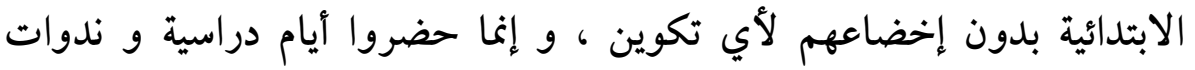

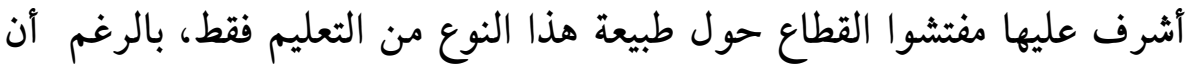

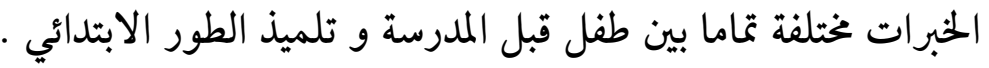

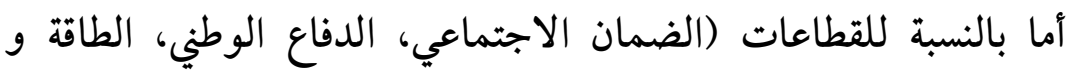

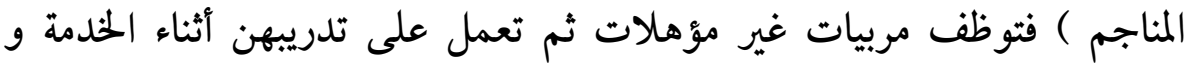

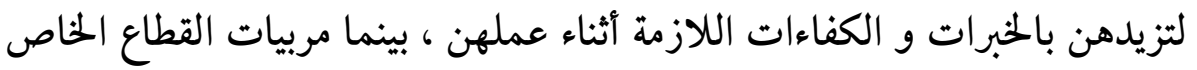

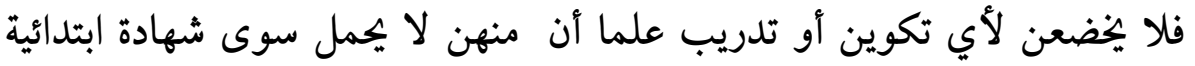

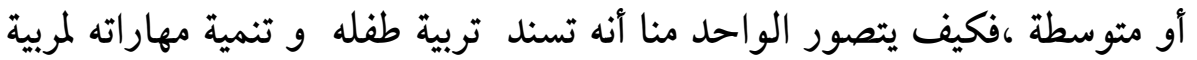

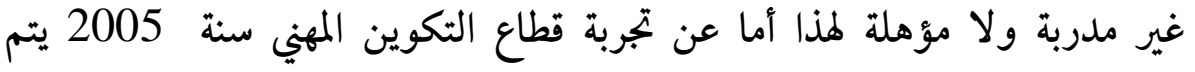

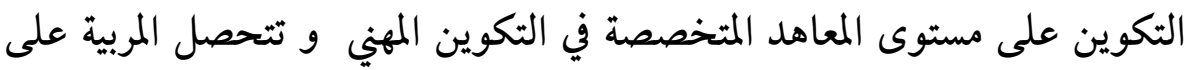

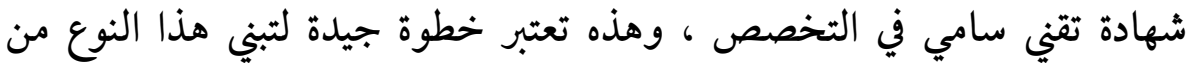




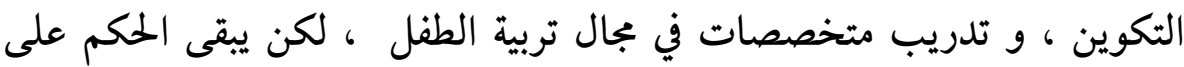

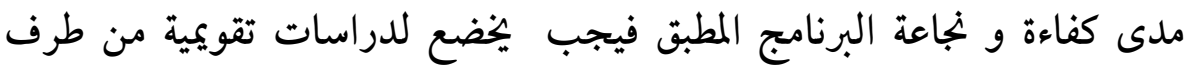

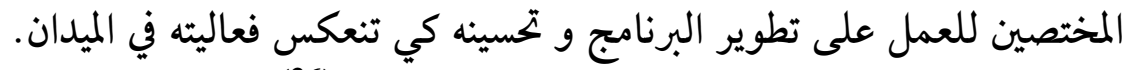

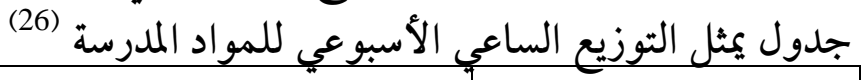

\begin{tabular}{|c|c|c|c|c|}
\hline \multicolumn{4}{|c|}{ مراحـــــل النكــــــــوين بالسداسي } & \multirow{2}{*}{ إلـــــــم } \\
\hline 4 & 3 & 2 & $\mathbf{1}$ & \\
\hline 02 & 02 & 02 & 02 & بيداغوجيا \\
\hline 02 & 02 & 02 & 02 & دراسة المحيط \\
\hline 06 & 06 & 08 & 08 & ت تربية فنية \\
\hline 04 & 06 & 08 & 08 & علم نفس النمو \\
\hline 02 & 02 & 02 & 02 & مدخل إلى علم النفس \\
\hline 04 & 06 & 08 & 08 & وقاية صحة و أمن \\
\hline 02 & -- & -- & -- & قانون العمل \\
\hline 02 & -- & -- & -- & منهجية \\
\hline 04 & -- & -- & -- & إعلام آلي \\
\hline-- & 02 & 02 & 02 & إتصال \\
\hline 08 & 08 & 04 & 04 & تربص \\
\hline
\end{tabular}




\section{خ الهوامسش والمراجع}

(1) محمد محمودالخو الدة، المنهاج الإبداعي الشامل في تريية الطفولة الأولى ، دار المسيرة الأردن، .2003

(2) شبل بدران، معلمة رياض الأطفال،دار المعرفة الجامعية الأسكندرية،2006ص25. (3)عبد اسميع، سهير محمد ، إعداد المعلم تنميته وتدريبه ،دار الفكر،الأردن ـ ،005 ،ص 24. (4)سهام بدر، التجامات الفكر التربوي في بجال الطفولة،مكتبة الفلاح، الكويت ، 2004

(5) عاطف عدلي فهمي:معلمة الروضة، دارالمسيرة ،الأردن، 2004، ص22 .

(6) ساسي نور الدين: نحو تصور مستقبلي لتكوين المعلم في ضوء المتغيرات العالمية، المنظمة

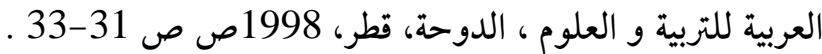
(7)المادة21 من الأمر 76/ 35،الجريدة الرسمية للجمهورية الجزائرية / العدد 75 بتاريخ 16 أفريل 1976

$$
\text { (8) (8) (8) (المرجع السابق. }
$$

(9) المادة 09 الجريدة الرسمية، العدد 33، بتاريخ 16 أفريل 1976. (10) تركي رابح: أصول التربية و التعليم، ديوان المطبوعات الجامعية ، الجزائر ، ط28، 88 1988

(12) الجريدة الرسمية للجمهورية الجزائرية / العدد 33 بتاريخ 16 أفريل 1976 (12)

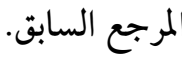

1984 ـأمصدر : وثيقة توجيهية تربوية سنة (14) القانون التوجيهي للتربية الوطنية رقم:08/ 04 المؤرخ في: 23 / 01/ 2008. (15) وزارة التربية الوطنية ، الدليل التطبيقي للتربية التحضيرية سن 5-6 ، 2004،ص67. 
(16) وزارة التربية الوطنية و مركز الأبحاث و الأنثربولوجيا الاجتماعية و الثقافية : الدليل المنهجي للتعليم ما قبل المدرسي ، الديوان الوطني للمطبوعات المدرسية ، الجزائر 1996. (17) فتيحة كركوش، سيكولوجية طفل ما قبل المدرسة ، ديوان المطبوعات الجامعية، بن

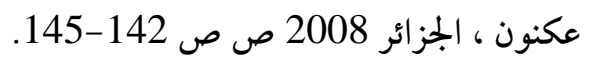

(18) المنشور الوزاري رقم:32 الخاص بالتدابير التنظيمية والتربوية الخاصة بالتربية التحضيرية

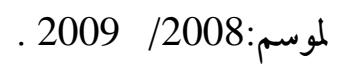
(19) المصدر: مديرة روضة الضمان الاجتماعي لولاية بسكرة 2010. (20) المصدر :مديرة روضة سونطر اك لولاية بسكرة 2010. (21)المصدر : المشرفة على روضة الدفاع الوطني لولاية بسكرة سنة 2010. (22) المصدر :مديرية النشاط الاجتماعي لولاية بسكرة 2010. (23)بجلس الوزراء المنعقد بتاريخ30.04.2002حول تنفيذ إصلاحات المنظومة الوطنية للتربية

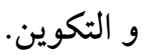
(24) مدونة تخصصات التكوين المهني لسنة 2005 ص 70. (25) مرجع تكوين تخصص مربيات الطفولة الأولى ، وزارة التكوين المهني 2005. (26) مرجع تكوين تخصص مربيات الطفولة الأولى ، وزارة التكوين المهني 2005. (15) وزارة التربية الوطنية ، الدليل التطبيقي للتربية التحضيرية سن 5-6 ، 2004،صريل 7. (16) وزارة التربية الوطنية و مركز الأبحاث و الأنثربولوجيا الاجتماعية و الثقافية : الدليل المنهجي للتعليم ما قبل المدرسي ، الديوان الوطني للمطبوعات المدرسية ، الجزائر 1996. (17) فتيحة كركوش، سيكولوجية طفل ما قبل المدرسة، ديوان المطبوعات الجامعية، بن

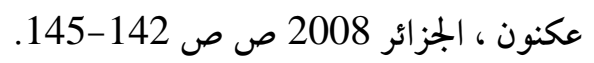


(18) المنشور الوزاري رقم:32 الخاص بالتدابير التنظيمية والتربوية الخاصة بالتربية التحضيرية

$$
\text { لموسم:2008/ 2009 } 2009 .
$$

(19) المصدر: مديرة روضة الضمان الاجتماعي لولاية بسكرة 2010. (20) المصدر :مديرة روضة سونطر اك لولاية بسكرة 2010. (21)المصدر : المشرفة على روضة الدفاع الوطني لولاية بسكرة سنة 2010. (22) المصدر :مديرية النشاط الاجتماعي لولاية بسكرة 2010.

(23)بجلس الوزراء المنعقد بتاريخ30.04.2002حول تنفيذ إصلاحات المنظومة الوطنية للتربية و التكوين.

(24) مدونة تخصصات التكوين المهني لسنة2005 ص 70. (25) مرجع تكوين تخصص مربيات الطفولة الأولى ، وزارة التكوين المهني 2005. (26) مرجع تكوين تخصص مربيات الطفولة الأولى، وزارة التكوين المهني 2005. 
العدد 01 مارس 2012 